\title{
In vitro and In vivo anti-inflammatory potential of isolated compounds from ethyl acetate extracts of Tecomaria capensis
}

\author{
K. Venkata Gopaiah', G. Kalyani', G. S. N. Koteswara Rao', E. Tamil Jothi ${ }^{2}$ \\ ${ }^{1}$ Department of Pharmaceutics, KL College of Pharmacy, Koneru Lakshmaiah Education Foundation, Deemed \\ to be University, Guntur, Andhra Pradesh, India, ${ }^{2}$ Department of Pharmacology, Devaki Amma Memorial \\ College of Pharmacy, Malappuram, Kerala, India
}

\begin{abstract}
Aim: The leaves of the plant Tecomaria capensis were extracted with different solvents and screened for antiinflammatory activity. Materials and Methods: The ethyl acetate extract of the plant $T$. capensis has showed the presence of flavonoids, glycosides, steroids, and terpenoids. Anti-inflammatory activity was investigated by carrageenan-induced method (in vivo) for isolated compounds from ethyl acetate extract of $T$. capensis leaves. Results and Discussion: The in vitro anti-inflammatory activity of the 3, 4 dihydro-2,2 dimethyl2H-benzochromene-5,6 dione and (3R)-3,7-dimethyloct-6-en-1-ol was concentration dependent. While in in vivo, the percentage reduction in the paw volume calculated at $3^{\text {rd }} \mathrm{h}$ for 3,4 dihydro-2,2 dimethyl-2Hbenzochromene-5,6 dione was 54.5\%, (3R)-3, 7-dimethyloct-6-en-1-ol was 77.3\%, and standard diclofenac was $79.6 \%$. Conclusion: This study demonstrates that isolated compounds of ethyl acetate extract of $T$. capensis have significant anti-inflammatory activities.
\end{abstract}

Key words: Anti-inflammatory activity, ethyl acetate, Tecomaria Capensis

\section{INTRODUCTION}

$\mathrm{P}$ lants have been one of the important sources of medicines even since the beginning of human civilization. ${ }^{[1]}$ Today, nearly $88 \%$ of the global population turn to plant-derived medicines as they are first line of defense for maintaining health and combating diseases. In the present study, an attempt has been made to enrich the knowledge of antiinflammatory activity of ethyl acetate extract of leaves of Tecomaria capensis (family: Bignoniaceae). It is also known as cape honeysuckle, a fast growing, scrambling shrub which may grow up to $2-3 \mathrm{~m}$ high and spread $>2.5 \mathrm{~m}$. T. capensis is an evergreen plant in warm climate areas but loses its leaves in colder areas. It has pinnately compound leaves that have oval leaflets with blunt teeth. Flowering time for this shrub is very erratic, and often, it flowers all year round. Flowers are orange in color. Plant is used as a traditional medicine to relieve pain and sleeplessness. Infusions of dried powdered bark are used for sleeplessness. ${ }^{[2,3]}$ It is included in the list of African plants evaluated for in vitro antiplasmodial activity. ${ }^{[4]}$

\section{MATERIALS AND METHODS}

\section{Plant Collection}

Matured leaves of T. capensis were collected in bulk in and around Guntur region, Andhra Pradesh, India. The coarse powder was passed through sieve No.60. The plant of T. capensis was identified by Professor Dr. S.M. Khasim, Department of Botany and Microbiology, Acharya Nagarjuna University, Guntur, Andhra Pradesh, India. The specimen (No: ANU/00129/2009/AP) was deposited in the Herbarium of the University Department of Botany and Microbiology for future reference.

\section{Address for correspondence:}

K. Venkata Gopaiah, Department of Pharmaceutics, K L College of Pharmacy, Koneru Lakshmaiah Education Foundation, Deemed to be University, Vaddeswaram, Guntur, Andhra Pradesh, India. Phone: +91-9966337164. E-mail: venkatgopi8789@gmail.com

Received: 01-12-2018

Revised: $15-12-2018$

Accepted: 21-12-2018 


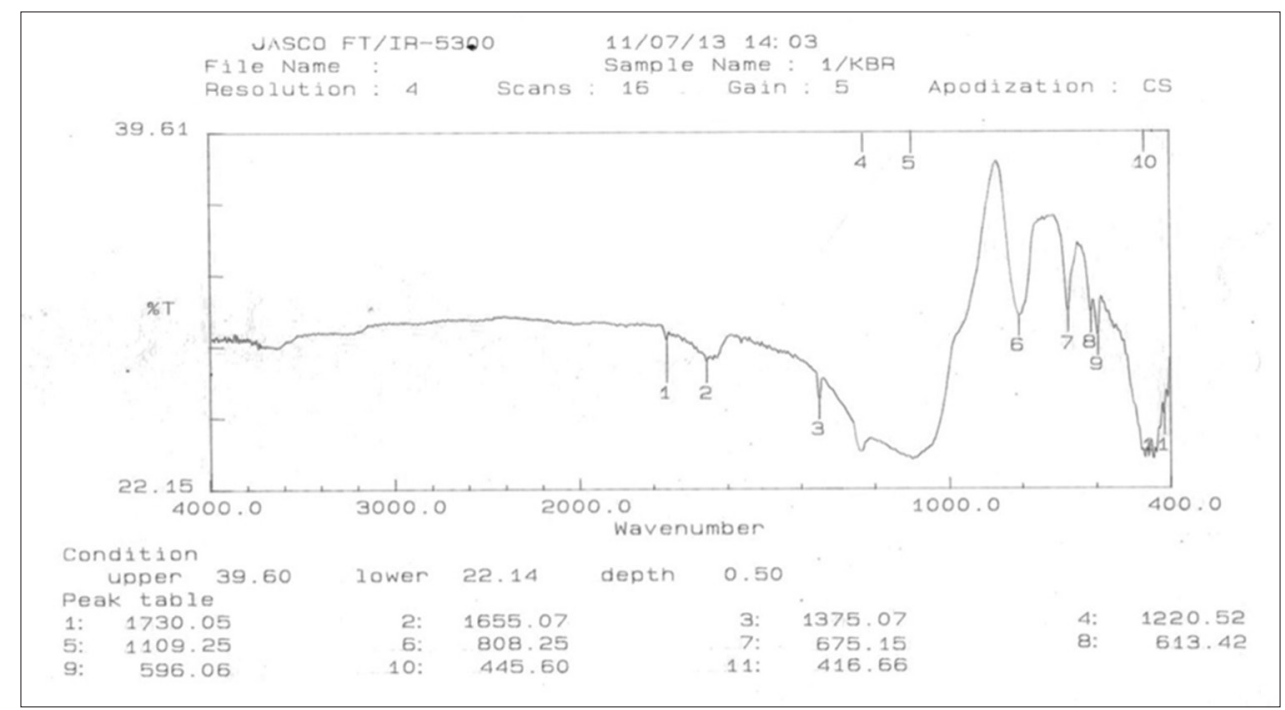

Figure 1: Infrared spectrum of 3, 4-dihydro-2, 2-dimethyl-2H-benzochromene-5, 6-dion

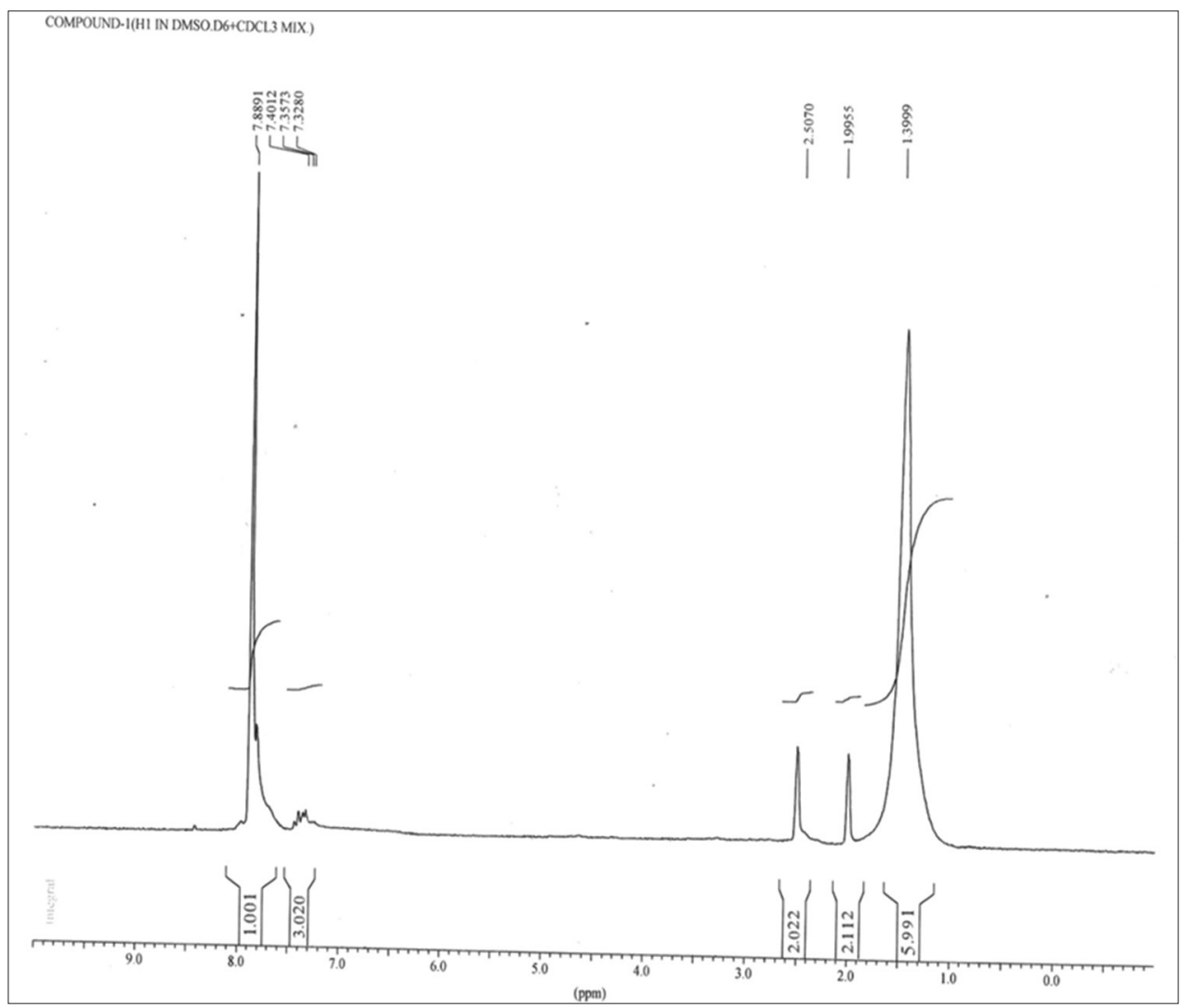

Figure 2: ${ }^{1} \mathrm{H}$ NMR spectrum of 3, 4-dihydro-2, 2-dimethyl-2H-benzochromene-5, 6-dion

\section{Extraction}

The leaves of $T$. capensis were separated from the stalks and thoroughly washed with running tap water and rinsed with double-distilled water. Then, the leaves were allowed for drying in shade and aerated at room temperature. The air dried leaves are pulverized using the mechanical grinder. This extract was prepared using Soxhlet apparatus. About $150 \mathrm{~g}$ of dried leaves powder was taken in a muslin cloth bag. The purified ethyl acetate was passed through the tube where the powder bag was kept. The ethyl acetate was passed through siphon tube until it reached the round bottom flask in which porcelain chips were provided. The vapors containing the constituents passed through the condenser and reached the tube containing powder bag, and the process was repeated. This was continued for $24 \mathrm{~h}$. Then, the round-bottom flask containing extract was transferred to a beaker and was allowed to evaporate in a water bath. This concentrated ethyl acetate extract was stored at room temperature and it is used for further analysis. 


\section{Composition Analysis}

A Fourier-transform infrared (FT-IR) is carried out in an instrument of JASCO 5300, analyzed using pressed pellet technique for different wave number identifications. Nuclear magnetic resonance (NMR) was carried out by Varian-NMR-600 spectrometer using tetramethylsilane as an internal standard. Standard pulse sequences were used for homo- and heteronuclear correlation experiments. ${ }^{1} \mathrm{H}$ NMR spectra were measured at $599 \mathrm{MHz}$, whereas ${ }^{13} \mathrm{C}$ NMR spectra were run at $150 \mathrm{MHz}$. Multiplicities of ${ }^{13} \mathrm{C}$ NMR resonances were determined by Distortionless enhancement through polarization transfer (DEPT). Liquid chromatography-mass spectrometry (LC-MS) analyses were carried out with a quadruple ion trap MS (SHIMADZU). The stationary phase was used as the type of C18 column (250 $\times 4.6 \mathrm{~mm}$ ) manufactured by Waters Column, Bengaluru, India. The mobile phase constitutes the Solvent A: $5 \%$ formic acid in water and Solvent B: Methanol (high-performance liquid chromatography [HPLC] Grade). The ultraviolet (UV) response during LC-MS was monitored at $360 \mathrm{~nm}$, the highest absorbance wavelength for each set of components as determined from prior HPLC studies. The LC/MS was operated in the positive operating mode using electron spray ionization source.

\section{Sheep Red Blood Cell (SRBC) Membrane Stabilization Method (In Vitro) ${ }^{[5,6]}$}

The anti-inflammatory activity for ethyl acetate extract of $T$. capensis leaves and isolated compounds from ethyl acetate extract of T. capensis was determined by SRBC membrane stabilization method. Blood was collected from sheep. The collected blood was mixed with equal volume of $2 \%$ dextrose, $0.8 \%$ sodium citrate, $0.05 \%$ citric acid, and $0.42 \%$ sodium chloride in water. The blood was centrifuged at $3000 \mathrm{rpm}$ and packed cells were washed with isosaline $(0.85 \%, \mathrm{pH} 7.2)$, and $10 \% \mathrm{v} / \mathrm{v}$ suspension was made with isosaline. The assay mixture contained the drug [concentration as mentioned in Table 1] with $1 \mathrm{ml}$ of phosphate buffer $(0.15 \mathrm{M}, \mathrm{pH} 7.4)$, $2 \mathrm{ml}$ of hyposaline $(0.36 \%)$ and $0.5 \mathrm{ml}$ of SRBC suspension. Diclofenac was used as the reference drug. Instead of hyposaline, $2 \mathrm{ml}$ of distilled water was used as control. All the assay mixtures were incubated at $37^{\circ} \mathrm{C}$ for $30 \mathrm{~min}$ and centrifuged. The hemoglobin content in the supernatant solution was estimated using colorimeter at $560 \mathrm{~nm}$. The percentage hemolysis was calculated by assuming the hemolysis produced in the presence of distilled water as $100 \%$. The percentage of SRBC membrane stabilization or protection was calculated using the following formula and the results are shown in Table 1.

\begin{tabular}{lccccccc}
\multicolumn{2}{l}{ Table 1: Effect of isolated compounds from ethyl acetate extract of $T$. capensis leaves by SRBC membrane } \\
stabilization method
\end{tabular}

*Values are expressed as mean \pm SEM $(n=6)$ animals, T. Capensis: Tecomaria capensis, SRBC: Sheep red blood cell

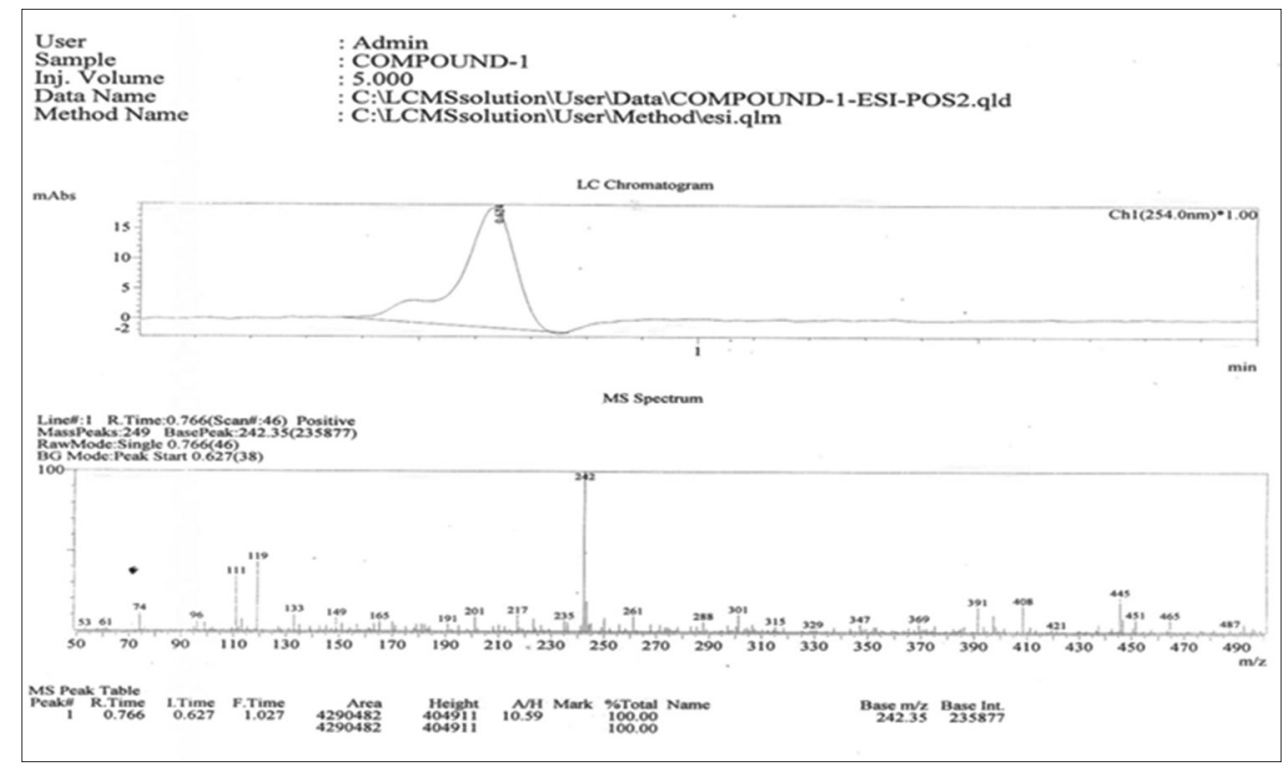

Figure 3: Liquid chromatography-mass spectrometry of 3, 4-dihydro-2, 2-dimethyl-2H-benzochromene-5, 6-dion 
$\%$ Membrane stabilization $=100-\left(\frac{\mathrm{OD} \text { of test }}{\text { OD of control }}\right) \times 100$

\section{Carrageenan-induced Hind Paw Edema (In Vivo)}

Either sex of animals weighing (150-200 g) was divided into six groups of six animals each. Group 1 was treated as control, Group 2 was treated as standard, Group 3 was treated as ethyl acetate extract low dose, Group 4 was treated as ethyl acetate extract high dose, Group 5 was treated as 1,2,3,9-tetrahydropyrrolo quinazoline-3,7-diol, and Group 6 was treated as 3,7-dimethyloct-6-en-1-ol. Paw edema was induced by $0.1 \mathrm{ml}$ of $1 \%$ carrageenan in physiological saline into subplantar tissues of the left hind paw of each rat in each group. Diclofenac sodium $(5 \mathrm{mg} / \mathrm{kg})$, ethyl acetate extracts (100 mg/kg and $200 \mathrm{mg} / \mathrm{kg}$ ), and isolated compounds $(10 \mathrm{mg} /$ $\mathrm{kg}$ ) were administered orally $30 \mathrm{~min}$ before carrageenan administration. Paw volume was measured at $1,2,3$, and $6 \mathrm{~h}$ by the mercury displacement method using a plethysmograph. The percentage inhibition of paw volume in drug treated group was compared with the control group. Results are shown in Table 2.

$$
\begin{aligned}
\text { Control }\left(\begin{array}{l}
\% \text { Increase in paw } \\
\text { volume in } 3^{\text {rd }} \mathrm{h}
\end{array}\right) \\
\text { \% Inhibition }=\frac{- \text { Test }\left(\begin{array}{l}
\% \text { Increase in paw } \\
\text { volume in } 3^{\text {rd }} \mathrm{h}
\end{array}\right)}{\text { Control }\left(\begin{array}{l}
\% \text { Increase in paw } \\
\text { volume in } 3^{\text {rd }} \mathrm{h}
\end{array}\right)} \times 100
\end{aligned}
$$

\section{RESULTS AND DISCUSSION}

To confirm the structure of the major compounds, these leaf ethyl acetate extracts were studied by $1 \mathrm{H}-\mathrm{NMR}$ technique. The chemical shift of the obtained NMR spectra was analyzed with those of the standard spectra of pure compounds with the help of laboratory-made software. The spectral parameters such as the concentration, low power decoupling, and temperature were the optimized conditions to provide good accuracy of the method. The present method allows for precise identification of major compounds present in the leaves. The compounds of 1,2,3,9-tetrahydropyrrolo quinazoline-3,7-diol and 3,7-dimethyloct-6-en-1-ol are identified. The method is very well suited for the isolated major components which were listed as follows:

\section{Compound: 1}<smiles></smiles>

3,4-dihydro-2,2-dimethyl-2 $H$-benzochromene-5,6-dione

Infrared (IR) Values: $1730(\mathrm{C}=\mathrm{O}), 1655(\mathrm{C}=\mathrm{C}), 1375(\mathrm{CH} 3)$, 1222.5 (C-O) [Figure 1].

${ }^{1} \mathrm{H}$ NMR Signals: A signal of 4H multiple 7.328-7.889 referred to aromatic ring, $2 \mathrm{H}$ singlet 2.507 and 1.995 are referred to two methylene group, and $3 \mathrm{H}$ singlet 1.399 referred to two methyl [Figure 2].

\section{Analytical Profile of Compound 1: 3, 4-dihydro-2, 2-dimethyl-2 $\mathrm{H}$-benzochromene-5, 6-dion}

$\mathrm{IR} \mathrm{V}_{\max }(\mathrm{KBr}) \mathrm{cm}^{-1}: 1730,1655,1375,1222.5$; Its IR values showed the following functional groups: $1730(\mathrm{C}=\mathrm{O}), 1655$ $(\mathrm{C}=\mathrm{C}), 1375\left(\mathrm{CH}_{3}\right)$, and $1222.5(\mathrm{C}-\mathrm{O})$.

${ }^{1} \mathrm{H}$ NMR $(\delta \mathrm{ppm}): 7.328-7.889(4 \mathrm{H}, \mathrm{m}), 2.507(2 \mathrm{H}, \mathrm{s})$,

\begin{tabular}{|c|c|c|c|c|c|c|}
\hline \multirow[t]{3}{*}{ Group } & \multicolumn{6}{|c|}{ Edema volume in $\mathrm{ml}$} \\
\hline & \multirow[t]{2}{*}{$1 \mathrm{~h}$} & \multirow[t]{2}{*}{$2 \mathrm{~h}$} & \multirow[t]{2}{*}{$3 \mathrm{~h}$} & \multirow[t]{2}{*}{$4 \mathrm{~h}$} & \multicolumn{2}{|c|}{$\%$ inhibition } \\
\hline & & & & & $3 \mathrm{~h}$ & $4 \mathrm{~h}$ \\
\hline Control & $0.47 \pm 0.09$ & $0.71 \pm 0.13$ & $0.88 \pm 0.17$ & $0.89 \pm 0.11$ & - & - \\
\hline Standard & $0.23 \pm 0.03$ & $0.21 \pm 0.12^{*}$ & $0.18 \pm 0.12^{*}$ & $0.16 \pm 0.07^{\star *}$ & 79.6 & 82.0 \\
\hline (3R)-3,7-dimethyloct-6-en-1-ol & $0.25 \pm 0.09$ & $0.22 \pm 0.12^{*}$ & $0.20 \pm 0.13^{*}$ & $0.18 \pm 0.04^{\star *}$ & 77.3 & 79.8 \\
\hline $\begin{array}{l}\text { 3,4-dihydro-2,2dimethyl-2H-benzochromene-5,6 } \\
\text { dione }\end{array}$ & $0.44 \pm 0.17$ & $0.49 \pm 0.1$ & $0.40 \pm 0.21$ & $0.37 \pm 0.22$ & 54.5 & 58.4 \\
\hline
\end{tabular}

Values are expressed as mean \pm SEM $(n=6)$ animals. Statistical significance test is carried out by one-way analysis of variables followed by Dunnett's test. ${ }^{*} P<0.05,{ }^{* *} P<0.01$ compared to control group, $T$. Capensis: Tecomaria capensis 
$1.995(2 \mathrm{H}, \mathrm{s}), 1.399$ (6H, s); Its ${ }^{1} \mathrm{H}$ NMR displayed a signal of $4 \mathrm{H}$ multiplet $7.328-7.889$ referred to aromatic ring, $2 \mathrm{H}$ singlet 2.507 and 1.995 referred to two methylene group, and $3 \mathrm{H}$ singlet 1.399 referred for two methyl groups

LC-MS m/z: 242.09 [Figure 3] (calculated for $\mathrm{C}_{15} \mathrm{H}_{14} \mathrm{O}_{3}, 242$ ).

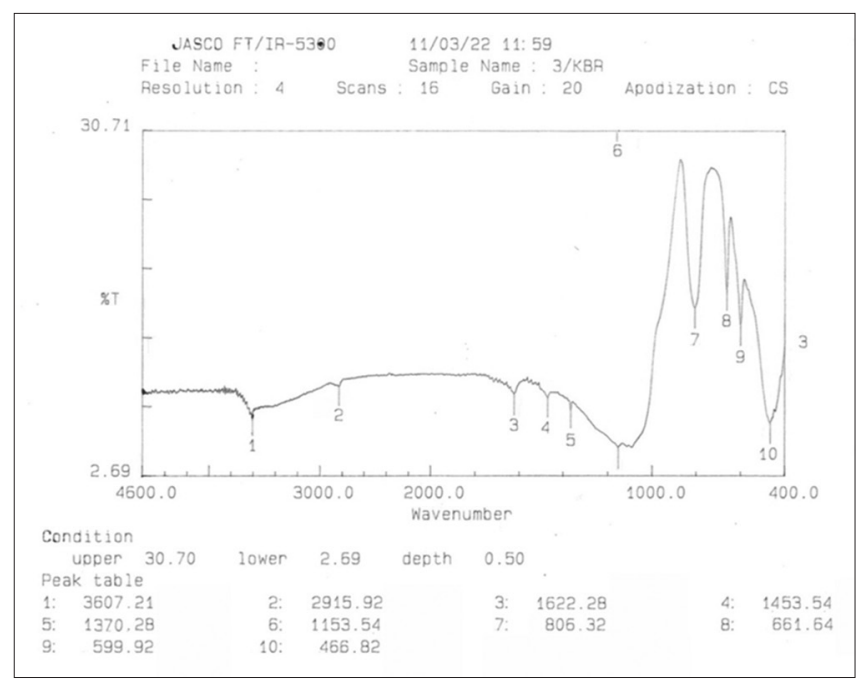

Figure 4: Infrared spectrum of 3,7-dimethyloct-6-en-1-ol
Compound: 2

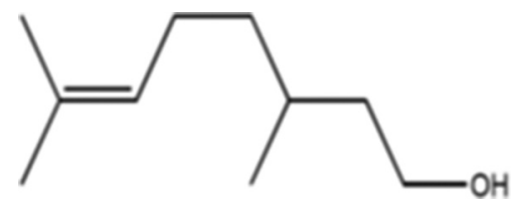

3,7-dimethyloct-6-en-1-ol

IR Values: $3607.21(\mathrm{O}-\mathrm{H}), 2915.92(\mathrm{C}-\mathrm{H}), 1622.28(\mathrm{C}=\mathrm{C})$, 1453.54 (CH2), 1370.28 (CH3), 1153.54 (C-O) [Figure 4].

1H NMR Signals: A signal of $6 \mathrm{H}$ singlet 1.777;

$3 \mathrm{H}$ singlet 1.06; four $2 \mathrm{H}$ singlet 1.29, 1.4, 1.96, and 3.11; and three $1 \mathrm{H}$ singlets with 6.927 referred to $\mathrm{OH}$ group, 5.267 referred to $\mathrm{CH}$ group, and 1.65 referred to $\mathrm{H}$ directly attached to carbon group [Figure 5].

LC-MS m/z: 156.15 (C10H20O) [Figure 6].

IR $\mathrm{V}_{\max }(\mathrm{KBr}) \mathrm{cm}^{-1} 3607.21,2915.92,1622.28,1453.54$, 1370.28, 1153.54.

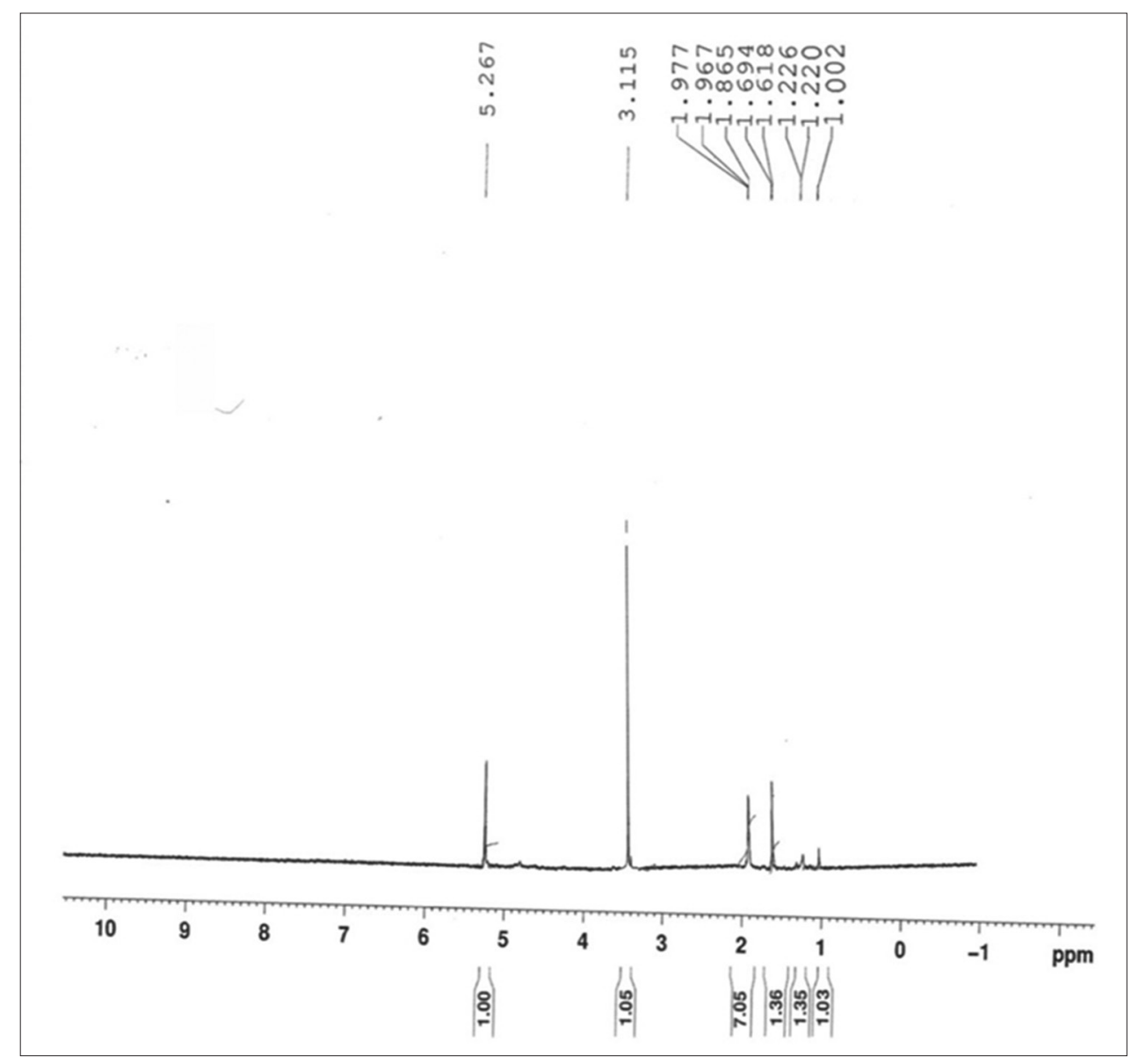

Figure 5: ${ }^{1} \mathrm{H}$ NMR spectrum of 3,7-dimethyloct-6-en-1-ol 


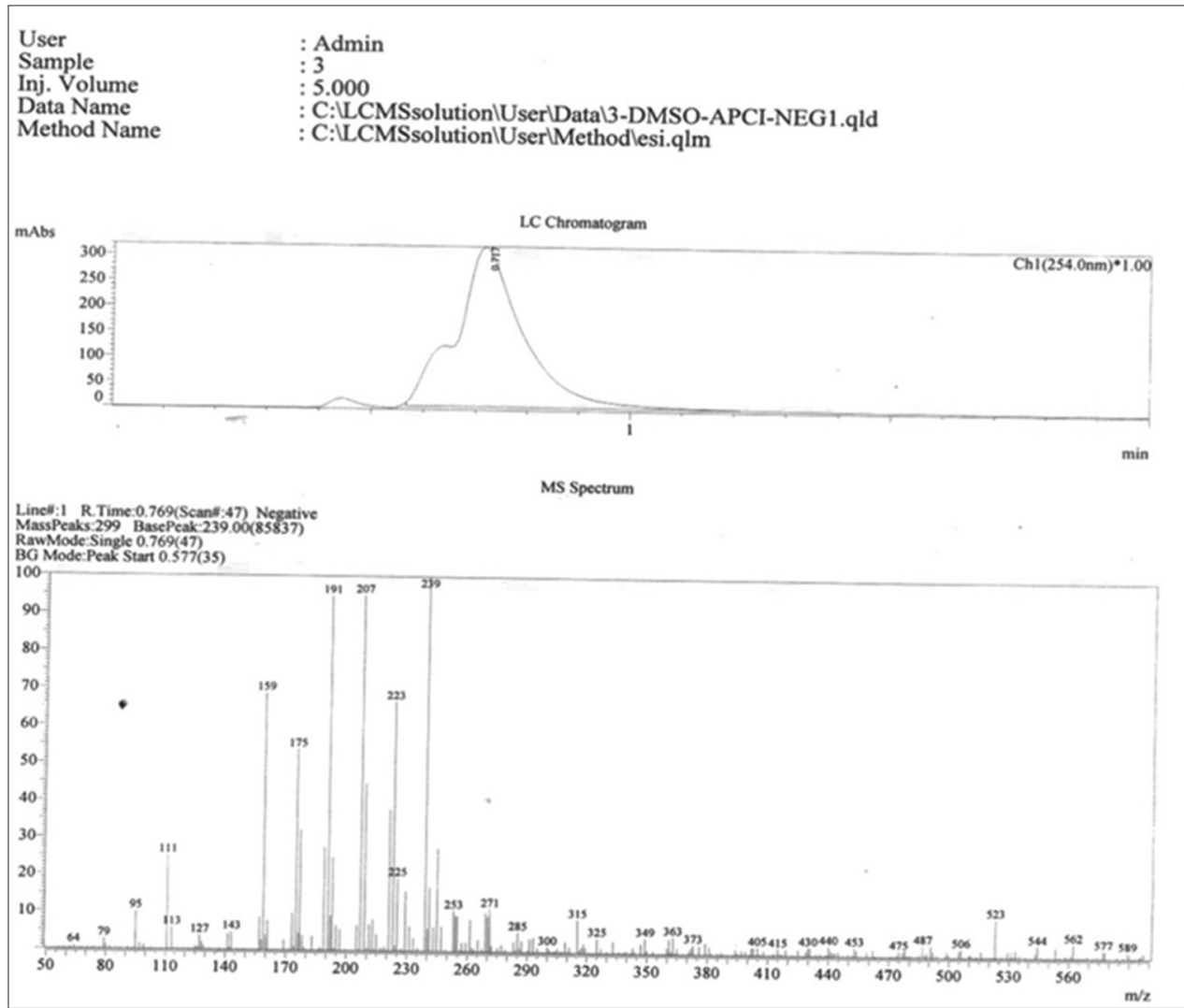

Figure 6: Liquid chromatography-mass spectrometry of 3,7-dimethyloct-6-en-1-ol

IR values showed the following functional groups: 3607.21 $(\mathrm{O}-\mathrm{H}), 2915.92(\mathrm{C}-\mathrm{H}), 1622.28(\mathrm{C}=\mathrm{C}), 1453.54\left(\mathrm{CH}_{2}\right)$, $1370.28\left(\mathrm{CH}_{3}\right)$, and $1153.54(\mathrm{C}-\mathrm{O})$.

${ }^{1} \mathrm{H}$ NMR $(\delta \mathrm{ppm}): 5.267(2 \mathrm{H}, \mathrm{s}), 3.115(2 \mathrm{H}, \mathrm{s}), 1.977-$ $1.865(10 \mathrm{H}, \mathrm{m}), \quad 1.656(2 \mathrm{H}, \mathrm{d}), \quad 1.223(2 \mathrm{H}, \mathrm{d})$, and $1.002(2 \mathrm{H}, \mathrm{s})$;

Its ${ }^{1} \mathrm{H}$ NMR displayed a signal of $6 \mathrm{H}$ singlet 1.777 ; $3 \mathrm{H}$ singlet 1.06; four $2 \mathrm{H}$ singlet $1.29,1.4,1.96$, and 3.11 ; and three $1 \mathrm{H}$ singlets with 6.927 referred to $\mathrm{OH}$ group, 5.267 referred to $\mathrm{CH}$ group, and 1.65 referred to $\mathrm{H}$ directly attached to carbon group

LC-MS m/z: 156.15 (calculated for $\mathrm{C}_{10} \mathrm{H}_{20} \mathrm{O}, 156.265$ ).

\section{SRBC Membrane Stabilization Method (In Vitro)}

Stabilization of SRBC membrane by hypotonicity-induced membrane lysis can be taken as an in vitro measure of antiinflammatory activity. SRBC stabilization method results are shown in Table 1. The compound (3R)-3, 7-dimethyloct6-en-1-ol isolated from ethyl acetate extract of $T$. capensis leaves had better anti-inflammatory activities in comparison to standard drug diclofenac. The anti-inflammatory activity of the 3, 4 dihydro-2,2 dimethyl-2H-benzochromene-5,6 dione and (3R)-3,7-dimethyloct-6-en-1-ol was concentration dependent. It was seen that the increase in the concentration leads to proportional increase in the activity. Lysosomal enzymes released during inflammation produce a variety of disorders which lead to tissue injury by damaging the macromolecules and lipid peroxidation of membranes which are assumed to be responsible for certain pathological conditions as heart attacks, septic shocks, and rheumatoid arthritis. The extracellular activity of these enzymes is said to be related to acute or chronic inflammation. Stabilization of lysosomal membrane is important in limiting the inflammatory response by inhibiting the release of lysosomal constituents of activated neutrophil such as bactericidal enzymes and proteases, which cause further tissue inflammation and damage on extracellular release by stabilizing the lysosomal membrane. SRBC or erythrocyte membrane is analogous to the lysosomal membrane. In the present study, the compounds 3,4 dihydro-2,2 dimethyl-2H-benzochromene-5,6 dione and (3R)-3,7-dimethyloct-6-en-1-ol isolated from ethyl acetate extract of $T$. capensis leaves produced anti-inflammatory activity. This activity may be produced due to inhibition of bactericidal enzyme and protease enzyme. Due to this enzyme inhibition, lysosomal membranes may be stabilized.

\section{Carrageenan-induced Hind Paw Edema (In Vivo)}

The significant ameliorative activity of the isolated compounds of ethyl acetate extract of $T$. capensis leaves and standard drug was observed. Results are tabulated in Table 2. The percentage reduction in the paw volume calculated 
at $3^{\text {rd }} \mathrm{h}$ for 3,4 dihydro-2,2 dimethyl-2H-benzochromene-5,6 dione was $54.5 \%$, (3R)-3, 7-dimethyloct-6-en-1-ol was $77.3 \%$, and standard diclofenac was $79.6 \%$. Carrageenaninduced rat paw edema is used widely as a working model of inflammation in the search for new anti-inflammatory drugs. The carrageenan-induced paw edema model in rats was known to be sensitive to cyclooxygenase inhibitors and had been used to evaluate the effect of non-steroidal antiinflammatory agents. ${ }^{[7,8]}$ The edema and inflammation induced by carrageenan were shown to be mediated by histamine and serotonin during first $1 \mathrm{~h}$ after which increased vascular permeability is maintained by the release of kinins up to $2 \mathrm{~h}$ $30 \mathrm{~min}$, followed by the release of kinins and finally through the release of bradykinin, prostaglandin, and lysosomes from $2 \mathrm{~h} 30 \mathrm{~min}$ to $6 \mathrm{~h}$. The later phase was reported to be sensitive to the most of the clinically effective anti-inflammatory agents. The mediators appear to be prostaglandins, the release of which was closely associated with migration of leukocytes into the inflamed site. ${ }^{[9]}$ These results indicate that the isolated compounds of T. capensis act in later phases in dose-dependent manner. Isolated compounds of $T$. capensis have inhibited the paw edema. It may be due to inhibition of the mediators of inflammation such as histamine, serotonin, and prostaglandin.

\section{CONCLUSION}

In the in vitro inflammatory trail, stabilization of SRBC membrane method was followed. The compound (3R)-3, 7-dimethyloct-6-en-1-ol isolated from $T$. capensis leaves had significant anti-inflammatory activity in comparison to standard drug diclofenac. The anti-inflammatory activity of the 3, 4 dihydro-2, 2 dimethyl-2H-benzochromene-5, 6 dione and (3R)-3,7-dimethyloct-6-en-1-ol was concentration dependent, and when the concentration increased, the activity was also increased. Hence, it may be concluded that the isolated quinone derived from lapachol (naphthoquinone) may be responsible for few of the therapeutic potential of the studied extract. Further studies are to be warranted for its safety, efficacy, and mechanism of action for its therapeutic potential.

In in vivo carrageenan-induced paw edema method, the compound (3R)-3, 7-dimethyloct-6-en-1-ol isolated from T. capensis leaves had significant anti-inflammatory activity in comparison to standard drug diclofenac. The anti-inflammatory activity of the 3,4 dihydro-2,2 dimethyl2H-benzochromene-5,6 dione and (3R)-3,7-dimethyloct6-en-1-ol were concentration dependent, and when the concentration increased, the activity was also increased. Hence, it may be concluded that the isolated quinone derived from lapachol (naphthoquinone) may be responsible for few of the therapeutic potential of the studied extract. Further studies are to be warranted for its safety, efficacy, and mechanism of action for its therapeutic potential.

\section{ACKNOWLEDGMENT}

The authors would like to thank the authority of K L College of Pharmacy, KLEF Deemed to be University, for their support and continuous encouragement throughout the project.

\section{REFERENCES}

1. Amaral L, Viveriros M, Kristiansen JE. The resistance phenomenon in microbes and infectious disease vectors. Trop Med Int Health 2001;6:1016-22.

2. Roberts M. Indigenous Healing Plants. South Africa: Halfway House, Southern Book Publishers; 1990.

3. Hutchings A, Scott AH, Lewis G, Cunningham AB. Zulu Medicinal Plants: An Inventory. Pietermaritzburg: University of Natal Press; 1996.

4. Pillaya P, Maharaj VJ, Smith PJ. Investigating South African plants as a source of new antimalarial drugs. J Ethnopharmacol 2008;119:438-54.

5. Shenoy S, Shwetha K, Prabhu K, Maradi R, Bairy KL, Shanbhag $\mathrm{T}$, et al. Evaluation ofanti-inflammatory activity of Tephrosia purpurea in rats. Asian Pac J Trop Med 2010;3:193-5.

6. Georgewill OA, Georgewill UO, Nwankwoala RN. Antiinflammatory effects of Morninga oleifera lam extract in rats. Asian Pac J Trop Med 2010;3:133-5.

7. Guang MY, Dong W, Wei T, Anti-inflammatory and antioxidant activities of Oxytropis falcata fractions and its possible anti-inflammatory mechanism. Chin J Natl Med 2010;285-92.

8. Prajapati RP, Kalariya M, Parmar SK, Sheth NR. Phytochemical and pharmacological review of Lagenaria sicereria. J Ayurveda Integr Med 2010;1:266-72.

9. Di Rosa M, Giroud JP, Willoughby DA. Studies on the mediators of the acute inflammatory response induced in rats in different sites by carrageenan and turpentine. J Pathol 1971;104:15-29.

Source of Support: Nil. Conflict of Interest: None declared. 